\title{
Transferência de conhecimento em empresas multinacionais estudo de caso na indústria de papel
}

\section{Antonio José Morais Cunha}

\author{
Mestre em Administração pela PUC Minas.
}

Marta Araújo Tavares Ferreira

\section{Professora Associada da UFMG.}

A pesquisa, aqui relatada, teve por objetivo avaliar o processo de transferência de conhecimento, envolvendo a subsidiária brasileira, a matriz americana e a subsidiária francesa de uma organização multinacional do setor de papel, buscando identificar os elementos de sucesso e o modelo de transferência adotado. Como base para a pesquisa, foram utilizados principalmente os modelos de transferência de conhecimento desenvolvidos por Duguid e Brown (2001), Nonaka e Konno (1998), Dixon (2000) e Fleury; Oliveira Junior; Child (2001). A pesquisa teve caráter qualitativo e foi realizado um estudo de caso único, valendo-se de entrevistas semiestruturadas, análise de documentos e observação para a coleta de informações. A pesquisa apontou, como fatores de sucesso da transferência, a adequada seleção dos coordenadores e dos participantes das equipes envolvidas, o apoio da organização, o estabelecimento de um programa de viagens, visitas, reuniões e atividades de socialização, que motivaram os participantes e apoiaram o desenvolvimento de relações de confiança entre as equipes, facilitando o compartilhamento de conhecimento. Como principais barreiras à transferência, foram apontadas a resistência à mudança por parte de alguns membros da equipe da unidade brasileira, associada à frustração com o fluxo unidirecional de conhecimento e a não valorização do conhecimento local.

Palavras-chave: Transferência de conhecimento; Transferência de tecnologia; Transferência de conhecimento em multinacionais. 


\section{Knowledge transfer in multinational companies: case study in the paper industry}

This research had as objective the evaluation of a knowledge transferring process within a multinational organization, involving subsidiaries in Brazil and France, focusing on the identification of elements of success and the operating model associated to the process. Research works done by Oliveira Junior and Fleury (2001), Duguid and Brown (2001), Nonaka and Konno (1998) and Dixon (2000) related to knowledge transfer were used as theoretical reference. Case study was used as research method, collecting data through documents analyzes, interviews and direct participation. As results this research identified as elements of success to design a knowledge transferring process the selection of coordinators and team members in each site that participated in the process, the organization support, the establishment of a program involving trips, site visits, meeting and other activities that support socialization, motivation and that help to develop a high degree of confidence among participants, so enhancing knowledge sharing.

Keywords: Knowledge transfer; Technology transfer; Knowledge and technology transfer in multinationals.

Recebido em 07.06.2011 Aceito em 12.12.2011

\section{Introdução}

As empresas vivem hoje, um cenário crescente de competição em um mercado global, em uma disputa cada vez mais acirrada pela permanência ou, como alguns preferem, pela sobrevivência. A expansão das empresas multinacionais tem conferido a estas corporações um poder sem precedentes (FLEURY; OLIVEIRA JUNIOR; CHILD, 2001).

Sob a ótica da inovação, a criação de subsidiárias em diversos mercados tem resultado no desenvolvimento e produção de novos produtos e processos ou na adequação local de produtos desenvolvidos pela matriz; em ambos os casos, a gestão do conhecimento assume um importante papel na interação entre a matriz e a subsidiária (SUBRAMANIAM; VENKATRAMAN, 2001). 
As empresas transnacionais representam hoje, uma parcela significativa de todo o esforço inovador, superando em muito as universidades e entidades governamentais. De acordo com Rodrigues (2001, p. 94), as organizações transnacionais concentram $80 \%$ dos gastos privados e civis em P\&D, desempenhando um importante papel na transformação de conhecimento em inovação.

Tanto sob a ótica da diferenciação quanto sob a ótica de redução de custos, a capacitação técnica e de inovação são a chave para o sucesso das organizações multinacionais e, em ambos os casos, a transferência de conhecimento é essencial para que as subsidiárias atinjam o nível de capacitação esperado e para que a matriz possa beneficiar-se do conhecimento delas oriundo.

Sendo a inovação o elemento chave das organizações modernas, o sucesso em criar um ambiente inovador passa por se ter uma estrutura organizacional e processos apropriados que permitam que mudanças tecnológicas prosperem (TIDD; BESSANT; PAVITT, 2005). A estrutura organizacional não se limita aos elementos tradicionalmente reconhecidos como parâmetros de design organizacional, tais como: centralização, mecanismos de coordenação, tipos de agrupamento e formalização do comportamento (MINTZBERG, 1995), mas diz respeito, também, a elementos informais, presentes na estrutura das organizações, como: comunidades de prática e grupos de discussão. Para Mintzberg (1995), a estrutura organizacional representa a forma como as atividades e fluxos são organizados nas empresas: estruturas mais flexíveis, chamadas orgânicas, favorecem a transferência do conhecimento enquanto estruturas mais rígidas, chamadas mecanicistas, acabam por dificultá-la.

O estudo da forma como matriz e subsidiária se relacionam quanto à transferência de conhecimento, que elementos são facilitadores do processo, que conhecimento a matriz está disposta a partilhar, além da forma como as subsidiárias se relacionam entre si e o impacto dessas relações sobre sua capacidade inovadora, apresenta-se como um campo de grande interesse tanto acadêmico como prático. Assim, o presente artigo tem por objetivo avaliar o processo de transferência de conhecimento, envolvendo a subsidiária brasileira, a matriz americana e a subsidiária francesa de uma organização multinacional do setor de papel, buscando identificar os elementos de sucesso e o modelo de transferência adotado.

O objeto da pesquisa, aqui relatada, é uma empresa produtora de papéis especiais, localizada no Brasil, que foi adquirida por uma multinacional americana. Nos primeiros anos após a aquisição, um processo de intensa transferência de conhecimento foi estabelecido, sendo este o processo estudado aqui, mais especificamente, os mecanismos de colaboração associados ao processo de transferência de conhecimento entre a subsidiária brasileira, a matriz e outras subsidiárias reconhecidas como fontes de conhecimento. 


\section{Transferência de conhecimento}

Dada as suas características, o conhecimento configura-se para a empresa como um forte fator de diferenciação e destaque dos demais concorrentes. A administração do conhecimento gera vantagem competitiva sustentável, permitindo que este seja alavancado, já que duas pessoas que compartilham seus conhecimentos individuais frequentemente podem combiná-los para gerar um conhecimento inédito, diferente do que detinham anteriormente. O efeito sinérgico faz com que o conhecimento resultante seja maior que a soma dos conhecimentos individuais.

Dados e informações não são conhecimento. Dados são fatos e variáveis coletados e armazenados com o objetivo de gerar uma base bruta a ser trabalhada, como parte do processo de construção do conhecimento. Ao tratarmos os dados pelo uso de ferramentas estatísticas ou gerando gráficos, mapas, esquemas visuais e relatórios, estamos, na verdade, produzindo informação, embora muitos confundam informação com conhecimento (NONAKA; TAKEUCHI, 1997). Conhecimento é o resultado da interpretação das informações, sendo atualmente reconhecida sua existência sob duas formas: explícita, quando o mesmo pode ser facilmente armazenado (procedimentos, regras de conduta, registros escritos, transcrições de conversas, arquivos eletrônicos, gravações, vídeos, etc.), sendo mais fácil sua transferência e seu compartilhamento; ou tácita, associada aos indivíduos ou grupos de indivíduos (NONAKA; TAKEUCHI, 1997).

O conhecimento se origina nas pessoas, sendo o resultado da interpretação das informações, formado à luz de suas experiências e vivências. Em sua forma mais primitiva, o conhecimento é tácito e se encontra arquivado no cérebro dos indivíduos. Desta forma, é único, intangível e difícil de ser replicado. Pode, ainda, ser compartilhado, formando o conhecimento coletivo possuído por uma comunidade.

O conhecimento pode tornar-se explícito pela externalização do conhecimento tácito, sendo este um dos maiores desafios do gerenciamento do conhecimento. Na organização, o conhecimento estaria explicitado na forma de diferentes repertórios, histórias, rotinas, práticas, regras e valores organizacionais (NONAKA; TAKEUCHI, 1997; DUGUID; BROWN, 2001).

De maneira holística, podemos afirmar que o processo de criação e compartilhamento de conhecimento caracteriza-se como um processo contínuo, em que o conhecimento flui pela organização, envolvendo indivíduos e tecnologia e, ainda, abrangendo conhecimento tácito e explícito (NONAKA; TAKEUCHI, 1997).

Um dos pontos recorrentes, quando abordamos a gestão do conhecimento, é a questão da colaboração necessária para que o fluxo de conhecimento ocorra na organização, já que o repositório original do conhecimento é o cérebro humano. As organizações precisam da colaboração dos indivíduos para que o seu conhecimento se torne "conhecimento organizacional". A colaboração do indivíduo pode ocorrer 
de duas formas: tornando explícito seu conhecimento (através de registros escritos, vídeos, gravações, registro de discussões e outros meios já mencionados) ou pela transferência do conhecimento para outros indivíduos, gerando o conhecimento tácito em grupo (NONAKA; TAKEUCHI, 1997).

Ao explorar a literatura, diversas modelagens foram identificadas relacionadas com a forma com que indivíduos e grupos dentro das organizações interagem (colaboram) com o objetivo de criar e transferir conhecimento. Dentre os diferentes modelos identificados, quatro foram selecionados, com o objetivo de desenvolver o modelo analítico desta pesquisa:

a) tradutores, operadores do conhecimento e objetos de fronteira, que configuram a arquitetura colaborativa apresentada por Duguid e Brown (2001), que se baseia no conceito de comunidades de prática e em como o conhecimento é transferido entre elas. Determinados indivíduos exercem funções não formais relacionadas com a interação entre as comunidades que participam da transferência de conhecimento;

b) construção de $\mathrm{Ba}$, modelo baseado em Nonaka e Konno (1998), que identifica um "espaço" onde o conhecimento é criado e transferido em espiral a partir do indivíduo, passando pelos grupos de indivíduos e se transformando em conhecimento explícito da organização. Existem quatro diferentes $\mathrm{Ba}$ relacionados com a natureza e forma de transferência de conhecimento;

c) agentes focalizadores, modelo que trata a transferência de conhecimento sob a ótica de redes, onde elementos posicionados em diferentes pontos da rede atuam como elementos de transferência do conhecimento entre organizações (Oliveira Junior; FLEURY; Child in Oliveira Junior; FLEURY, 2001); e

d) transferência de conhecimento prático (common knowledge), modelo baseado nos trabalhos de Dixon (2000), que assume que o conhecimento está presente em toda a organização, em contínua evolução mesmo em tarefas mais simples, e que não é possuído apenas por especialistas reconhecidos pelas organizações como fonte do conhecimento. Em seu modelo, Dixon (2000) desenvolveu cinco sistemas de transferência aplicáveis em diferentes contextos.

\subsection{Fatores de sucesso da transferência}

Apesar das diferenças de abordagem dos quatro modelos de transferência citados, é possível estabelecer um conjunto de fatores de sucesso em processos de transferência de conhecimento, comuns aos quatro. 
Primeiramente, os quatro modelos apontam a transferência de conhecimento como um processo essencialmente dependente dos indivíduos. Para Nonaka e Takeuchi (1997), o conhecimento está no cérebro dos indivíduos, é o resultado da interpretação de dados à luz de suas vivências e experiências. Para que a organização tenha acesso ao conhecimento, é preciso que as pessoas estejam dispostas a cedê-lo, torná-lo explícito, compartilhá-lo (NONAKA; TAKEUCHI, 1997; BROWN; DUGUID, 1998), para que o conhecimento tácito se converta em conhecimento explicito, nos procedimentos, manuais, práticas, fórmulas e especificações da organização.

Com uma visão existencialista que impregna a sociedade japonesa e suas organizações, Nonaka e Konno (1998) adaptaram o conceito de "Ba" ao contexto corporativo, como plataforma para o avanço do conhecimento individual e coletivo. O "Ba" origem é o "Ba" dos indivíduos, a equipe, o espaço onde os indivíduos compartilham suas experiências e vivências; ele se amplia para o "Ba" das equipes, que é a organização, que, por sua vez, se amplia para o "Ba" das organizações, que é o mercado.

Para Dixon (2000), quando pedimos a alguém que compartilhe parte do seu conhecimento, estamos pedindo que compartilhe algo pessoal. Para Fleury; Oliveira Junior; Child (2001), indivíduos com posicionamento chave na rede, identificados como atores focalizadores, agem como pontos de ligação, sendo responsáveis pelo compartilhamento do conhecimento na rede corporativa.

Sendo o indivíduo o elemento central no processo de transferência de conhecimento, sua disposição em participar do processo, compartilhar, emerge como um dos fatores determinantes para o sucesso. Sob esta ótica, Dixon (2000) destaca como fato relevante os benefícios, não necessariamente materiais (reputação, prestígio, admiração), que os indivíduos obtem ao partilhar seus conhecimentos. Para Nonaka e Konno (1998), no "Ba" original os indivíduos compartilham sentimentos, emoções, experiências e modelos mentais motivados pela simpatia ou, mais além, pela empatia por outros indivíduos, removendo as barreiras existentes. Do "Ba" original emergem a preocupação com o outro, a confiança e o comprometimento. No caso das comunidades, que são as células de conhecimento do modelo de Duguid e Brown (2001), os indivíduos estão comprometidos com um projeto compartilhado, um empreendimento comum resultante de um processo coletivo de negociação, e por partilharem um mesmo repertório de símbolos, crenças e valores (CHANAL, 2004). Sob a perspectiva de redes, a cooperação entre os atores é relacionada com os seus objetivos, não fazendo sentido o investimento na transferência de conhecimento em uma aplicação sem interesse para o parceiro.

A importância da socialização é comum aos quatro modelos apresentados. Para Nonaka e Konno (1998), a socialização envolve o compartilhamento do conhecimento tácito entre os indivíduos, quando esse conhecimento é trocado em atividades conjuntas, tais como: passar tempo juntos e viver em um mesmo local, em lugar de instruções escritas ou comunicadas verbalmente. A captura do conhecimento ocorre em um 
contexto de proximidade física. Ao descreverem a importância da narração de "estórias de campo" entre os técnicos de máquinas copiadoras, quando estes se encontram na sala de café e trocam experiências relacionadas ao reparo de equipamentos, Duguid e Brown (2001) reforçam que, a despeito de contarem com manuais detalhados e de terem recebido intenso treinamento na execução de reparos de máquinas copiadoras, o sucesso de tais profissionais está fortemente associado à troca de experiências e vivências no dia a dia, à transferência do conhecimento tácito aprendido a duras penas, muitas vezes ao longo de horas de trabalho para solucionar um defeito que não consta nos manuais nem treinamentos.

Também para Dixon (2000), enquanto a transferência de conhecimento explícito pode ser obtida através de procedimentos, padrões, especificações e manuais, apoiada pelo uso de tecnologia de comunicação e interação, o conhecimento tácito requer o estabelecimento de processos de transferência que envolvem contato físico.

Na transferência de conhecimento sob a perspectiva de rede, Fleury; Oliveira Junior; Child (2001) apontam a participação dos atores focalizadores em atividades que se relacionam com a socialização, tais como visitas a outras unidades reconhecidas como "centros de excelência", reuniões de equipes funcionais e períodos de treinamentos de média duração (algumas semanas). As atividades, neste caso, são importantes para reforçar o compartilhamento de informações entre as diferentes unidades e as atividades de socialização reforçam mais a transferência do conhecimento explícito, diferentemente dos outros três modelos.

Quando o assunto é o apoio da organização ao processo de transferência de conhecimento, os modelos apontam-no como fator de sucesso no processo de transferência. Para Nonaka e Konno (1998), a criação do "Ba" deve ser um esforço organizacional. É a organização que fornece os elementos necessários à criação e manutenção do "Ba", como nos exemplos da Sharp, Toshiba e Maekawa, que desenvolveram projetos que ilustram a implantação do espaço para criação do conhecimento, o "Ba". Fleury; Oliveira Junior; Child (2001) citam a participação em viagens, treinamentos e contatos com outros indivíduos como exemplos do suporte conferido aos atores focalizadores, no sentido de reforçar os laços entre atores, que estão posicionados em diferentes pontos da rede.

A existência de uma equipe preparada para receber o conhecimento e a mente aberta de que detém o conhecimento são dois fatores adicionais de sucesso na transferência. A não ser no caso mais simples de transferência, qual seja, a transferência de uma fábrica completa de um país para outro, identificada por Leornard-Barton (1995) como o processo mais básico de capacitação tecnológica, a equipe que recebe 0 conhecimento deve estar preparada e conhecer os princípios nos quais a tecnologia (entendida aqui como conhecimento) está baseada. Este requisito cresce à medida que consideramos níveis mais complexos de transferência do conhecimento, tais como a capacidade de executar o redesenho de produtos $\mathrm{e}$, mais à frente, a capacidade de executar projetos independentes. No caso da equipe que transfere o conhecimento, 
Leonard-Barton (1995) aponta a sua capacidade de também receber conhecimento como bastante relevante, principalmente em empresas com atuação global, em que questões locais, tais como o tipo de escrita (em softwares na China) e o adequado dimensionamento de equipamentos (como, por exemplo, o tamanho de equipamentos de cozinhas industriais no Japão), devem ser consideradas no projeto inicial de produtos que pretendem ser globais.

Para Nonaka e Konno (1998), o "Ba" de interação, no qual, de forma consciente, o conhecimento tácito é convertido em explícito, requer a seleção de indivíduos com características específicas e capacitados para trabalho em equipe, forças tarefas e equipes multifuncionais. Segundo Dixon (2000), a capacidade de absorção da equipe que recebe o conhecimento tem impacto significativo no resultado da transferência. Os indivíduos devem conhecer suficientemente o assunto que é objeto da transferência de conhecimento, para que possam absorver o novo conhecimento.

\subsection{Barreiras à transferência de conhecimento}

No caso das barreiras, AL-GHASSANI et al. (2006) cita a sobrecarga de trabalho como uma barreia à transferência de conhecimento, principalmente no caso do conhecimento tácito, que requer tempo, dedicação e tarefas adicionais dos profissionais envolvidos no processo. A participação em tais processos, em conjunto com as atividades inerentes às funções habituais dos participantes, pode sobrecarregar os profissionais e ter conseqüências sobre o alcance dos objetivos de transferência de conhecimento.

A dispersão geográfica entre os elementos que compõem o processo de transferência de conhecimento - bases de conhecimentos, fontes de conhecimentos e usuários - é apontada como outra barreira que requer uma coordenação central da organização (AL-GHASSANI et al., 2006).

A natureza do conhecimento, tácito ou explicito, e a sua conversão bem sucedida de uma forma a outra são aspectos essenciais relacionados com o sucesso da transferência e, em contrapartida, são também apontados como barreiras ao processo, visto que, dependendo da natureza do conhecimento, elementos de sucesso diferentes precisam ser garantidos e limitações precisam ser minimizadas. Cada tipo de conhecimento requer sistemas apropriados de gestão que garantam a codificação, transferência e assimilação (AL-GHASSANI et al., 2006; SUBRAMANIAM; VENKATRAMAN, 2001).

Zander e Kogut (1992) apresentam a questão da linguagem profissional como uma barreira à transferência do conhecimento, principalmente quando o conhecimento é transferido entre diferentes grupos funcionais, como, por exemplo, a área de P\&D e a produção. 


\section{Procedimento metodológico}

O objeto desta pesquisa é uma empresa produtora de papéis especiais, localizada no Brasil, que foi adquirida por uma multinacional americana e que vivenciou, a partir deste acontecimento, importante processo de transferência de conhecimento entre 1998 e 2003. Este processo ficou conhecido internamente como "know how transfer" e foi responsável pela capacitação técnica que permitiu que à subsidiária brasileira ampliar sua presença no mercado externo, saindo de uma posição em que pouco exportava para a posição vivida em 2010, em que o volume exportado representou mais de $50 \%$ da produção da empresa, servindo a todo o mercado latino americano e exportando para América do Norte, Europa e África.

A pesquisa baseou-se na análise dos documentos gerados ao longo do processo de transferência de conhecimento, por membros da equipe que participaram do projeto, e em oito entrevistas em profundidade com profissionais que participaram da transferência e com membros da alta administração da empresa.

Ao todo, foram analisados sessenta documentos internos da organização, datados do período 1998/2003, tais como: relatórios de progresso das equipes de transferência de tecnologia, memorandos entre unidades, apresentações e reuniões de progresso com a alta administração, planos de ação, atas de reunião e contratos. Os documentos foram lidos e analisados, sendo seus principais aspectos resumidos sob a forma de fichas.

As entrevistas foram conduzidas de forma semi-estruturada; os entrevistados foram incentivados a falar sobre o processo de transferência de conhecimento e perguntas foram feitas com o objetivo de facilitar o desenvolvimento dos depoimentos. As entrevistas foram gravadas, transcritas e posteriomente analisadas.

A análise de dados foi realizada de forma concomitante com a etapa de coleta de dados, permitindo eventuais redirecionamentos do trabalho de coleta, com o objetivo de explorar as diferentes perspectivas que emergiram paulatinamente.

\section{Estudo de caso na indústria de papel}

A Corporação Produtora de Papel Especial (CPPE) surgiu em meados dos anos 90, através de um processo de "spin-off". A nova empresa foi formada por unidades fabris especializadas em um segmento específico de papel, que não mais interessava a um grande produtor global de papéis.

O tipo de papel produzido pela CPPE não era comercializado diretamente para o público consumidor, sendo, na verdade, matéria prima para produção de bens de consumo. O número de clientes era relativamente reduzido, todos produtores de produtos de consumo de massa.

Em 1998, a CPPE era líder mundial no seu segmento de atuação. A matriz da empresa localizava-se nos Estados Unidos. Naquele país, 
localizavam-se, também, duas unidades produtoras e outras quatro unidades produtoras estavam na França (uma delas adquirida em 1998). A subsidiária francesa, apesar de não ser a sede da empresa, desfrutava de grande prestígio e poder dentro da organização em função da qualidade superior de seus produtos, da maior dispersão e tamanho de seu mercado, do maior volume de produção e, finalmente, por sua maior lucratividade.

O mercado onde atua a CPPE se apresentava bastante segmentado, com pelo menos quatro grandes competidores globais e diversas empresas atuando de forma local, fornecendo a mercados regionais. A CPPE estava bem posicionada nos mercados europeu e americano, no entanto, buscava reforçar seu posicionamento estratégico e considerava na época a aquisição de outras empresas.

Na América do Sul, existiam três empresas locais que atuavam no mesmo segmento da CPPE, entre elas a Unidade Brasileira (UB), que, apesar de fornecer basicamente para o mercado brasileiro, desempenhava um papel importante, já que o Brasil representava aproximadamente cinquenta porcento do mercado latino americano.

A UB era um fabricante de papel que desfrutava de boa reputação no mercado brasileiro (atuava em diversas linhas de produto), contava com uma equipe técnica bem preparada, tinha a certificação ISO 9001 desde 1994 (foi uma das primeiras a obtê-la no segmento de papel no Brasil), e contava com um bom parque industrial, mas carecia de adequação tecnológica ao segmento de produtos de maior valor agregado, que a empresa elegeu como sua linha de negócios central. A UB fornecia, com exclusividade, a um dos maiores consumidores brasileiros do papel especial produzido pela CPPE e tinha fortes relações com o referido cliente.

Em 1998, a CPPE adquiriu a UB e, desta forma, concretizou um objetivo de significativa importância em sua estratégia de expansão: 0 posicionamento no mercado latino americano. O Brasil era um dos maiores mercados consumidores de sua linha de produtos e a UB estava bem posicionada no mercado brasileiro, detendo mais de oitenta porcento deste. Para a UB, concretizou-se o acesso ao conhecimento e à tecnologia que Ihe faltavam.

\subsection{0 processo de transferência de conhecimento}

Ao adquirir a UB, a CPPE foi bem sucedida em estabelecer contratos de longa duração (três anos de fornecimento exclusivo com cláusulas de renovação) com clientes chaves no Brasil, Argentina e Chile. Para tanto, os produtos deveriam ser produzidos na UB.

Mesmo antes da concretização da aquisição, já era clara a necessidade de um processo de transferência de conhecimento da CPPE para a UB, de forma a capacitá-la tecnicamente a produzir produtos equivalentes aos produzidos pela CPPE. A partir do momento que a UB passou a fazer parte da CPPE, sua capacitação para produzir produtos equivalentes aos da CPPE assumiu prioridade máxima. 
A capacitação da UB buscou contemplar duas linhas de negócios: a linha de negócios TP e a linha de negócios CG. Em ambas as linhas de negócio, a transferência foi segmentada em duas áreas principais: a de produto, onde o foco central era o desenvolvimento do portfólio da UB, e a de processo produtivo, com foco no aumento de produtividade e melhoria de qualidade.

Em março de 1998 (um mês após a concretização da aquisição legal), foi produzido um relatório, apontando as áreas que deveriam ser priorizadas no processo de transferência de conhecimento.

Apesar do processo de transferência de conhecimento ter sido logo em seu início, formalizado pela empresa em um contrato firmado entre a matriz e a UB, a sua implantação se deu de forma adaptativa, tanto que, apesar da existência do documento que o formalizava, os entrevistados declararam que o processo havia se iniciado informalmente e que só posteriormente havia assumido uma forma mais institucionalizada, levando a crer que os entrevistados não tinham conhecimento do contrato em questão.

A transferência do conhecimento estudada passou por uma série de tentativas, até que um processo maduro tomasse forma. As principais mudanças relacionadas com a organização, contatos, forma de o processo operar, entre outras, ocorreram nos primeiros 12 meses; a partir daí, o processo de transferência tornou-se mais maduro e a forma de trabalho, mais clara.

Logo nos três meses iniciais, o processo foi liderado pelo diretor de engenharia (DE) da UA, não porque ele fosse o mais indicado, mas simplesmente pelo fato do processo de aquisição ter sido conduzido pela matriz e o envolvimento do DE no processo de diligência antes da compra ter facilitado seu contato com a equipe da UB. Nesse momento inicial, que consistiu basicamente da troca de informações e da formulação de um melhor diagnóstico das necessidades da UB, um grupo de profissionais brasileiros passou a interagir com o diretor de engenharia da UA; este gupo trabalhava havia muito na UB, e compartilhava valores e práticas.

A partir do momento em que foram identificados os pontos críticos que deveriam ser trabalhados, o diretor de engenharia da UA passou a buscar recursos da sua unidade para participar do processo. Na UA, formou-se uma estrutura similar à formada na UB, com uma equipe que compartilhava valores, práticas e que tinha como objetivo o sucesso do processo. Os coordenadores passaram a assumir um papel importante de ligação entre as unidades e de identificação de pessoas e recursos a serem envolvidos.

Passados aproximadamente três meses, o diretor de Engenharia da UF assumiu a coordenação geral do processo de transferência, indicado pelo Chief Operations Officer (COO), que era francês e acumulava a posição de presidente da UF, por este não estar satisfeito com a condução inicial do processo.

De forma geral, no primeiro ano do projeto, a participação foi majoritariamente da equipe americana. Como coordenador geral, o diretor de engenharia da UF passou a inserir a equipe técnica da UF no processo 
de transferência, com aumento da participação dos técnicos franceses, a partir do último trimestre do primeiro ano. Nesse período, a transferência de conhecimento estava estruturada, havia coordenadores, equipes e processos de "fornecimento de conhecimento" estabelecidos, tanto na UA quanto na UF, com uma coordenação de esforços entre as duas.

Ao final de 1998, o diretor de engenharia da UA saiu da organização e, com sua saída, a participação americana na transferência de conhecimento relacionada com o processo produtivo (engenharia e processo) foi praticamente descontinuada. Manteve-se a participação da UA na área de desenvolvimento de produto, que perdurou durante todo o processo de transferência, com intensa participação de seu cientista sênior (que posteriormente se tornou o diretor de P\&D da empresa), em função do reconhecimento interno e por parte dos clientes de seu conhecimento. Sua participação em reuniões com clientes foi fundamental para a construção de uma imagem de competência da equipe da UB.

Neste ponto, dois subprocessos de transferência estavam estabelecidos: um associado com a transferência de conhecimento do processo produtivo, envolvendo equipes de engenharia e produção da UF e UA; outro relacionado com o conhecimento em matéria de desenvolvimento de produtos, envolvendo equipes de P\&D da UA e UB. $O$ gerente técnico da UB participava das duas equipes e atuava como elemento de ligação entre elas. Os dois subprocessos tinham a coordenção geral do diretor de engenaria da UF.

Algumas informações contidas nos documentos analisados ajudaram a esclarecer a maior participação da equipe francesa:

a) as unidades francesas eram reconhecidas, tanto internamente quanto pelos clientes, como produtoras com mais qualidade de uma boa parcela do portfólio de produtos da empresa;

b) a unidade americana foi responsável pelo processo de aquisição e o diretor de engenharia daquela unidade fez parte do grupo que analisou a empresa e estabeleceu os primeiros contatos. Assim, pelo lado americano, a transferência de conhecimento estava centrada no diretor de engenharia, sendo ele o membro da UA mais implicado no projeto. Sua aposentadoria ao final de 1998, não foi adequadamente coberta, deixando um vazio na administração dos recursos de engenharia da UA, que apoiava o processo de transferência de conhecimento para a UB;

c) a equipe americana estava dispersa pelas fábricas, o que dificultava sua atuação, tendo seus componentes sido selecionados pelo diretor de engenharia da UA. Um dos participantes americanos comentou que, em sua primeira viagem ao Brasil, conheceu seu companheiro de equipe no próprio aeroporto;

d) a equipe francesa tinha experiência em processos semelhantes com outras unidades, além de ter uma equipe de engenharia estruturada e centralizada, que servia a todas as fabricas; e 
sendo o coordenador geral do processo de transferência de conhecimento o Diretor de Engenharia da França, ele administrava com mais facilidade seus próprios recursos.

Com a interrupção da participação do grupo americano, a equipe francesa de engenharia passou a participar de forma mais ativa e com maior liberdade para implantar mudanças alinhadas com sua linha de conhecimento e com menos.

Após um período de maior intensidade de participação dos desenvolvedores da UA, a transferência conhecimento na área de desenvolvimento de produto passou a incluir indivíduos também da UF e evoluiu para uma situação de equilíbrio entre a participação dos dois grupos (UA e UF), sendo esta decidida em função do tipo de produto em desenvolvimento e do conhecimento específico necessário, em linha com o fato da área de P\&D estar organizada de forma corporativa.

Ao longo dos anos o processo de transferência de conhecimento (internamente conhecido como know how transfer) cresceu em matéria de profissionais envolvidos e de número de subprojetos. Pelo menos trinta e cinco profissionais da UB e da CPPE participaram do processo e mais de vinte subprojetos foram conduzidos. No caso da transferência de conhecimento relacionada com o processo produtivo, dois grupos centrais participaram de praticamente todo o processo: um grupo de quatro profissionais da UB e outro de quatro profissionais da UF, incluindo o diretor de engenharia.

\subsection{0 sucesso no processo de transferência de conhecimento}

O sucesso do processo foi tema constante da documentação, pontuado pela resolução das deficiências técnicas, pela superação de metas de vendas, pela entrada em novos mercados, pelo ganho de qualidade e lançamento de novos produtos. Na ótica do então presidente da UB, o processo de transferência de conhecimento foi bem sucedido, atingindo seu objetivo principal de capacitar tecnicamente a UB para produzir produtos de classe mundial. Foram apontados como resultados:

a) de 1998 a 2002, a UB aumentou sua produção em aproximadamente $16,0 \%$ e suas exportações praticamente quadruplicaram;

b) de 1998 a 2003, foram desenvolvidos setenta novos produtos. Os novos produtos desenvolvidos passaram a compor 0 portifólio de produtos da empresa e já em 1999, mais de 20 $\%$ das vendas da UB estavam associados a novos produtos. Em 2000, atingiu-se o ápice, com os produtos novos representando mais de $30 \%$ das vendas da UB;

c) no período de 1998 a 2002, o desempenho no cliente do produto TP melhorou de forma significativa, com as de perdas no processo do cliente associadas ao papel reduzidas à metade. No mesmo período, a produtividade da máquina $C$, produtora dos produtos da linha TP, cresceu em torno de 
22\%. Quanto à qualidade, o índice de aglomerados de fibras (um dos parâmetros de qualidade desta linha de produtos) teve redução de $85 \%$ de novembro de 1999 a setembro de 2000, quando diversas modificações no processo produtivo (incluindo novos dispositivos) foram introduzidas, com o apoio do processo de transferência de conhecimento; e

d) no período de 1998 a 2000, a produtividade cresceu em torno de $13 \%$ para a máquina $B$ e em torno de $15 \%$ na máquina $A$, que produziam produtos da linha CG. Os ganhos de produtividade ocorreram, neste caso, praticamente sem investimentos, através de análises do processo de produção e eliminação de gargalos. A melhoria de qualidade foi um grande destaque nesta linha de produtos, com a redução da variação de porosidade da faixa de 9,5 a $11,0 \%$ em maio de1998 para valores menores que 8,0\% em junho de 2000 . Em alguns produtos, os resultados situaram-se abaixo de $7,0 \%$, atingindo de forma inequívoca o padrão mundial de excelência.

\subsection{Procedimentos para a transferência de conhecimento}

A principal forma adotada para o intercâmbio entre a UB e a demais unidades da CPPE, localizadas na Europa e Estados Unidos, foi a realização de visitas de grupos de técnicos à UB, para intensos período de reuniões. $\mathrm{Na}$ área de processo produtivo, agendas eram propostas e acordadas, e as visitas tinham, em geral, uma semana de duração. Durante as visitas, ocorriam reuniões técnicas e testes industriais, tanto relacionados com a questão tecnológica quanto com o desenvolvimento de novos produtos. Após as reuniões e testes, era realizada uma reunião de fechamento com uma apresentação para a alta administração e posterior publicação de um relatório da viagem, normalmente emitido pelo grupo visitante. Em complementação às visitas ocorriam, também, conferências telefônicas e muita troca de correspondência escrita.

Juntamente com a agenda técnica da visita, ocorriam, também, atividades externas, tais como jantares e almoços. Tipicamente, sempre havia um "churrasco oficial", no qual toda a equipe que trabalhava no projeto de transferência de conhecimento era convidada a participar, juntamente com os principais gestores da organização. Tais atividades proporcionavam a oportunidade para contatos mais descontraídos, conversas relacionadas com aspectos pessoais como a família, hobbies, planos futuros, permitindo que os profissionais descobrissem afinidades e desenvolvessem relações de confiança.

No caso da transferência de conhecimento na área de desenvolvimento de produto, existiam visitas de cientistas e desenvolvedores de produto à UB, para discutir o desenvolvimento de novos produtos e participar de experimentos em máquinas para produção de protótipos e amostras, bem como visitas, seminários e workshops em clientes por grupos formados pelos técnicos da UB, da UF e da UA. Eram 
realizados jantares e almoços normalmente com clientes, mas o trabalho que precedia as visitas e seminários era, em si, uma oportunidade de maior contato entre os profissionais e de desenvolvimento de relações pessoais.

As visitas ao exterior de profissionais da UB, que trabalhavam com a transferência de conhecimento na área de desenvolvimento de produtos, foram relativamente frequentes em função da área de P\&D da CPPE estar estruturada com uma coordenação corporativa e, desta forma, ocorriam reuniões no exterior, para as quais os técnicos da UB eram convidados. Os técnicos da UB participavam de seminários e congressos com o objetivo de se capacitarem e aumentarem sua visibilidade e credibilidade junto aos clientes. No caso da equipe de transferência de conhecimento na área de processo e tecnologia de produção, as visitas ao exterior foram menos frequentes e direcionadas a aspectos específicos dos subprojetos.

A transferência de conhecimento na área de produto contou com um forte suporte do cientista sênior da UA, que trabalhou de forma intensa com o gerente técnico da UB na melhoria da qualidade dos produtos brasileiros, principalmente da linha de produtos TP. O trabalho conjunto se deu principalmente através de visitas aos clientes, para acompanhamento de testes e do uso dos produtos da UB. As visitas em clientes por técnicos da UB acompanhados pelo cientista sênior da UA, que desfrutava de reconhecida reputação no mercado, atenderam a diversos objetivos, principalmente:

a) a vivência do cientista sênior da UA em problemas similares em clientes no exterior, permitiu a elaboração de propostas de solução para os problemas relacionados com o uso do produto da UB, que, muitas vezes, estavam relacionados com 0 processo do cliente e não com o produto em si;

b) as visitas permitiram a transferência de conhecimento tácito para os técnicos da UB nas áreas de conhecimento consideradas críticas para a ampliação da participação no mercado; e

c) as visitas deram credibilidade aos técnicos da UB, através de um processo de transferência da reputação do cientista sênior da UA.

O fato da CPPE ser a líder no mercado, bem sucedida na colocação de seus produtos em mais de sessenta países, contando com um extenso portfólio, assegurou que houvesse pouco questionamento quanto à sua competência para fornecer conhecimento. Em contrapartida, o insucesso da UB em expandir-se no mercado sul americano enfraquecia qualquer postura de contestação da equipe local quanto às orientações e modificações apresentadas pelos técnicos da CPPE. Desta forma, o grupo encarregado de fornecer o conhecimento desfrutou de um grau relativamente alto de liberdade (e respaldo da alta administração) para mudar o que fosse necessário para que a UB atingisse 0 nível de competitividade das demais unidades da corporação, embora no início do processo tenha havido resistência, principalmente por parte do diretor de operações da UB. 
Não foi identificada competição entre a UB e as demais unidades da organização no período analisado. Na verdade, na área de conhecimento relativa ao desenvolvimento de novos produtos, os técnicos tanto da UA quanto da UF foram fortes aliados da UB junto aos clientes na substituição de competidores e no enfrentamento de produtos concorrentes que supostamente apresentavam desempenho superior aos produtos da filial brasileira.

O processo teve apoio da alta administração da empresa ao longo de todo o período analisado. Diversos documentos citam o apoio não só do presidente da UB, mas também de outros dirigentes da organização no nível corporativo, e vários documentos endereçados ao presidente da UB relatam a evolução do projeto, enquanto outros enviados por ele a técnicos de outras filiais questionam a evolução do processo.

Foram realizadas reuniões semestrais, envolvendo o CEO e o COO, quando o progresso dos trabalhos era apresentado. Os principais pontos dessas reuniões eram a expansão do mercado e o aumento de produtividade. Em alguns casos, as apresentações contavam com membros de outras unidades (França e Estados Unidos), que endossavam decisões da equipe brasileira quanto a investimentos e mudanças no processo.

\subsection{Fatores de sucesso do processo de transferência}

Ao atingir a maturidade, o processo de transferência de conhecimento consolidou-se como dois subprocessos, um relativo ao conhecimento na área de desenvolvimento de produto e o outro, na área do processo produtivo.

$\mathrm{Na}$ área de processo e engenharia, o processo de transferência se consolidou, envolvendo apenas a UF e a UB. Os coordenadores de cada uma das unidades desempenharam papéis fundamentais para o sucesso do projeto, tendo sido responsáveis por eliminar ou administrar as barreiras que poderiam impedir a transferência de conhecimento. Conduziram o projeto como atores focalizadores, de acordo com o modelo de Fleury; Oliveira Junior; Child (2001).

O estabelecimento de um programa de transferência de conhecimento com objetivos, reuniões e apresentação de resultados foi, também, de grande importância para o sucesso. Sob a perspectiva do modelo de Dixon (2000), houve uma "transferência distante", pois especialistas se deslocaram para o local onde era demandado o conhecimento, normalmente tácito, para trabalhar junto com a equipe local na solução de um problema de grande interesse para a organização.

$\mathrm{Na}$ área de desenvolvimento de produto, o processo de transferência de conhecimento foi incorporado ao programa corporativo de P\&D e, desta forma, contou com o apoio tanto da UA quanto da UF. A mobilização das outras unidades no sentido de apoiar a capacitação da UB e o desenvolvimento de relações pessoais foram mais importantes nesta área, principalmente no início do processo, e a transferência de conhecimento se assemelhou ao que é proposto por Duguid e Brown (1998), ou seja, as 
equipes de cada unidade funcionaram como comunidades de prática, em que alguns indivíduos atuaram como tradutores e outros, como operadores de conhecimento.

Em ambos os subprocessos, barreiras foram superadas. O processo como um todo foi apoiado e gerenciado pela alta administração, que monitorou os resultados alcançados, aspecto apontado como fundamental tanto por Nonaka e Konno (1998) quanto por Dixon (2000), que ressaltam também a importância da associação do processo de transferência com os objetivos da empresa e da implantação de ambientes favoráveis à inovação.

Um dos mecanismos ou aspectos operacionais mais importantes identificados no processo de transferência de conhecimento executado pela CPPE foi o programa de viagens e reuniões realizadas pelos participantes do processo. Tais viagens estiveram na verdade associadas a diversos fatores de sucesso identificados, tais como o desenvolvimento da confiança, a socialização e a motivação. Para Nonaka e Konno (1998), somente pela convivência em um mesmo ambiente, a vivência da cultura, forma de pensar e valores daqueles com quem se pretende compartilhar o conhecimento, os indivíduos são capazes de realizar de forma eficaz a transferência do conhecimento tácito que, no caso do processo de transferência analisado, era uma parcela importante do conhecimento a ser transferido. Ainda, sob a ótica de Nonaka e Konno (1998), as viagens da equipe francesa ao Brasil e as intensas semanas de trabalho, com testes e reuniões, combinadas com atividades externas, propiciaram períodos dedicados à troca de experiência entre as equipes, bastante próximos do conceito de $B a$ de interação.

Considerando-se o modelo de conhecimento distribuído de Dixon (2000), a dinâmica do processo de transferência de conhecimento estudado faz com que as viagens e reuniões sejam associadas ao conceito de "Transferência Distante" em que especialistas são envolvidos em um processo intenso de troca de conhecimento essencialmente tácito para atacar problemas específicos não rotineiros. As principais características mencionadas por Dixon (2000), neste caso, são: o conhecimento tácito é carregado por especialistas pela organização sendo sua aplicação "traduzida" de acordo com a necessidade local; o conhecimento, neste caso, não é aplicável, até que seja ajustado às condições onde está sendo aplicado. Ao analisarem um caso da transferência de conhecimento em empresa de serviços, Fleury; Oliveira Junior; Child (2001) também apontaram as viagens e reuniões como importantes atividades relacionadas com 0 processo de transferência de conhecimento, constatando que os indivíduos que centralizavam o fluxo de informações entre as diferentes unidades da organização participavam de seminários e reuniões e se deslocavam por algumas semanas para departamentos de outras subsidiárias.

Outro fator importante foi o papel desempenhado pelos coordenadores do processo, com destaque para o coordenador geral do processo, o diretor de engenharia da UF. Sob a ótica de Fleury; Oliveira Junior; Child (2001), os coordenadores ocupavam uma posição 
privilegiada na rede de relacionamentos da organização e desta forma puderam atuar como atores focalizadores, favorecendo 0 fluxo de conhecimento entre as unidades e disponibilizando recursos para o projeto. A atuação do coordenador geral do processo pode ainda ser analisada sob a ótica de Duguid e Brown (2001) como um operador do conhecimento, transacionando o conhecimento entre as comunidades. No caso do coordenador do processo da UB, sua atuação também foi importante, administrando as frustrações associadas ao fluxo unidirecional e impositivo de conhecimento e aprendendo a lidar com a forma de pensar da equipe francesa, de modo que, ao final do processo, a equipe brasileira desenvolveu os meios para ter seus conhecimentos incorporados aos projetos.

No entanto, diferentemente do modelo de atores focalizadores do processo preconizado por Fleury; Oliveira Junior; Child (2001), os coordenadores não centralizaram o fluxo de comunicação, mas na verdade facilitaram a interação entre os grupos que detinham o conhecimento e os grupos que demandavam o conhecimento. Os critérios identificados na escolha dos coordenadores foram sua influência, reputação e disposição em participar do processo, características que Ihes permitiram mobilizar os recursos necessários para apoiá-lo, confirmando o que é apresentado por Nonaka e Konno (1998) ao enunciarem as características a serem buscadas nos indivíduos selecionados para apoiarem a criação de "Ba" pelas empresas.

Outro fator de sucesso foi a seleção dos indivíduos que participaram das equipes; os critérios adotados apontaram para profissionais com experiência profissional, hábeis em trabalho em equipe e com profundo conhecimento das áreas que eram alvo de melhorias na UB. No caso do processo de transferência de conhecimento na área de processo e produção, a equipe da UF era formada basicamente por engenheiros da área de projetos, que compartilhavam a mesma linguagem, valores e práticas. A equipe da UB era formada na sua maioria por engenheiros químicos que trabalhavam juntos por pelo menos doze anos, todos com formação especializada na produção de papel, e que também compartilhavam a mesma linguagem, valores e práticas. As duas equipes tinham muitos elementos comuns, o que foi fundamental para ultrapassar a barreira à transferência representada pelas diferenças na linguagem profissional (ZANDER; KOGUT, 1992).

A capacitação de quem recebe o conhecimento foi também identificada como um fator de sucesso no processo de transferência de conhecimento, confirmado no caso estudado. Para Dixon (2000), a equipe receptora deve ter algum conhecimento relacionado com a área de aprendizagem para que possa absorver o novo conhecimento. A autora não limita este conhecimento somente aos aspectos técnicos, mas considera, também, o conhecimento sobre como trabalhar em equipe ou liderar um projeto. Para Duguid e Brown (2001), a transferência de conhecimento é favorecida quando os indivíduos compartilham a linguagem profissional, pois, segundo Zander e Kogut (1992), esta pode configurar-se como uma barreira ao processo. 
Em contrapartida, a organização de quem fornece o conhecimento foi identificada como um fator importante para o sucesso da transferência. O grupo de engenharia da matriz não estava organizado para transferir o conhecimento e sua participação estava fortemente ancorada no diretor de engenharia; a súbita saída deste da empresa evidenciou o fato.

O desenvolvimento da confiança entre os participantes despontou como o fator mais importante para o sucesso do processo de transferência, mencionado por todos os entrevistados. De fato, os quatro modelos estudados (DUGUID; BROWN, 2001; NONAKA; KONNO, 1998; DIXON, 2000 e FLEURY; OLIVEIRA JUNIOR; CHILD, 2001) apontam que compartilhar o conhecimento, principalmente o tácito, envolve 0 desenvolvimento de relacionamentos entre os indivíduos. Os entrevistados associaram o desenvolvimento da confiança a diferentes momentos do processo; em muitos casos reforçando outros elementos de sucesso, tais como a motivação para participar.

Para o cientista sênior da UA, a participação em atividades complementares às atividades profissionais tais como jantares, conversas de bar e viagens, permitiram o desenvolvimento de relações de confiança. Outro fator gerador de confiança, segundo ele, foi a busca de uma maior integração com a cultura e hábitos locais (NONAKA; KONNO, 1998).

O desenvolvimento da confiança entre os participantes é uma conquista e não pode ser considerado como algo que surge a partir do momento em que se forma a equipe. O gerente de operações brasileiro relatou que, durante pelo menos dois anos, teve a percepção que havia censura nas informações passadas pela equipe da França. Apenas com o passar dos anos houve aumento do número de subprojetos coordenados exclusivamente por técnicos brasileiros, indicando um maior grau de confiança tanto na questão do sigilo das informações, que era uma das principais preocupações desde 0 início do processo, quanto na competência técnica.

Os relatos do cientista sênior da UA e do gerente de operações reforçam o que é mencionado por Nonaka e Konno (1998), Dixon (2000) e Duguid e Brown (2001): o desenvolvimento do ambiente que permite se compartilhar o conhecimento demanda tempo, e mesmo havendo a orientação por parte da alta administração que o conhecimento seja compartilhado, isto pode acabar não acontecendo se as condições fornecidas pela organização não facilitarem o contato direto entre os participantes.

Dixon (2000) esclarece que a transferência do conhecimento explicito é em geral mais fácil, por ser desprovida do sentimento de ser algo pessoal que está sendo transferido, pois o conhecimento explicito é encarado como pertencente à organização. Já o conhecimento tácito, que se constrói quando um indivíduo, diante de uma situação que não consta nos manuais, combina suas observações com suas vivências, é visto como pessoal e necessita de um ambiente de confiança. $t$

A socialização, identificada pelos quatro modelos como um dos fatores de sucesso no processo de transferência de conhecimento, principalmente quando se busca transferir conhecimentos tácitos, foi 
também um fator importante para que os objetivos do caso de transferência estudado fossem atingidos. Tanto na transferência de conhecimento relacionado com 0 processo produtivo quanto na transferência do conhecimento relacionado com o desenvolvimento de produtos, constantes encontros presenciais entre as equipes para reuniões de trabalho, visitas a clientes e acompanhamento de experiências permitiram a socialização.

O apoio da organização, mencionado por Nonaka e Konno (1998), Dixon (2000) e Fleury; Oliveira Junior; Child (2001), foi também essencial para o sucesso do projeto. Esse apoio foi demonstrado na construção das equipes, na autorização de viagens, na aprovação de subprojetos. Em contrapartida, a empresa estabeleceu objetivos e cobrou resultados. As reuniões envolvendo o Chief Executive Officer (CEO), o Chief Operations Officer (COO) e o Presidente da UB reforçaram o apoio da organização.

Fechando o conjunto de fatores de sucesso ligados à organização, outro elemento identificado foi $o$ fato de o conhecimento transferido se relacionar com uma necessidade da UB e ser de grande relevância para a organização. Sob a ótica do modelo de conhecimento distribuído (DIXON, 2000), a transferência de conhecimento envolvendo diferentes equipes, quer seja próxima, distante ou estratégica, deve ser sempre motivada por objetivos do negócio. Para Fleury; Oliveira Junior; Child (2001), a transferência de conhecimento só faz sentido se interessar aos atores da rede envolvidos no processo.

$\mathrm{Na}$ questão da motivação, diversos elementos estiveram presentes no processo analisado. Um dos aspectos motivadores mais importantes foi a visibilidade conferida ao processo dentro da organização. Neste aspecto particular, as reuniões no Brasil envolvendo o CEO, o COO e o presidente da unidade brasileira desempenharam um importante papel. Conforme mencionado por Dixon (2000), os indivíduos se sentem motivados a participar de processos de transferência de conhecimento na medida em que identificam benefícios pessoais. Neste caso, a exposição diante de níveis mais altos da organização trouxe prestígio para a equipe que transferia o conhecimento e desenvolveu um sentimento de competência naqueles que receberam. Os coordenadores da UB e da UF ressaltaram a motivação relacionada com o sucesso na execução das tarefas que Ihes foram designadas.

\subsection{Principais barreiras ao processo de transferência}

Um dos aspectos apontados pelos entrevistados da UB como uma barreira enfrentada no processo de transferência foi a resistência à mudança por parte de alguns membros da equipe da UB, associada à frustração com o fluxo unidirecional de conhecimento e a não valorização do conhecimento local.

De forma geral, houve boa receptividade da UB à transferência, já que, a empresa já estava cansada de estar isolada, sem acesso ao conhecimento, e a possibilidade de transferência de conhecimento de uma empresa que por anos era reconhecida com a melhor do setor, foi vista 
como uma grande oportunidade. No entanto, o processo ocorreu em uma só direção, sem levar em consideração a possibilidade de transferir conhecimento da unidade brasileira para as outras unidades. A equipe brasileira tinha a expectativa de que o processo viesse a combinar conhecimentos da UB com o conhecimento da UA e da UF, o que não aconteceu. Mais que isto, os eventuais questionamentos de recomendações da UF foram encarados de forma bastante negativa.

Para o cientista sênior da UA, sob a ótica da UA eles estavam ali para ensinar, passar para os brasileiros a maneira certa de fazer as coisas: a maneira americana. Somente após conhecer melhor a UB, os colegas da nova unidade, os clientes e os projetos, percebeu-se que também existia o que aprender.

Ao analisar o caso, foi possível perceber que, ao longo do processo, a postura dos fornecedores de conhecimento mudou, passando a uma postura mais cooperativa, porém em geral prevaleceu a posição das afiliadas externas. As propostas desenvolvidas pela UB sofriam criticas e eram dificilmente adotadas. Então, a equipe da UB passou a trabalhar as propostas de forma que estas parecessem originadas na equipe da UF. Adotando esta estratégia, os conflitos foram minimizados e a equipe brasileira foi bem sucedida em implantar conceitos desenvolvidos por ela própria.

Mesmo assim, segundo o gerente de operações, o processo de transferência unilateral gerou frustração na equipe brasileira, principalmente pelo fato de ter sido verificado em algumas viagens de técnicos brasileiros a outras unidades 0 uso de algumas práticas brasileiras, sem o reconhecimento de sua autoria.

Outra barreira observada foi a constatação de que havia a intenção de manter uma certa vantagem técnica por parte da equipe que estava compartilhando o conhecimento. Apesar da orientação para que ocorresse a transferência de conhecimento e tecnologia de forma irrestrita, as visitas de integrantes da UB a unidades da CPPE eram relativamente raras (e havia restrições quanto ao registro fotográficos dos processos), o que de certa forma limitou o acesso ao conhecimento ao que era apresentado pelos técnicos em suas visitas ao Brasil. A partir do momento que uma relação de confiança foi plenamente estabelecida (passados aproximadamente dois anos) e que foi permitido um maior acesso ao processo produtivo como um todo, de forma mais aberta e sem limitações, os técnicos da UB passaram a perceber que nem tudo era transferido, de forma que a UF sempre mantivesse uma vantagem sobre a UB. Leornard-Barton (1995) menciona ter observado este comportamnto (limitações na transferência plena do conhecimento) em diversos casos estudados, motivado pelo desejo da empresa transmissora de guardar o poder em suas mãos.

A distância entre as unidades, apontada na literatura com uma das barreiras à transferência de conhecimento, não foi identificada como um fator dificultador do processo analisado, o que indica ter havido um bom planejamento das visitas, reuniões, trocas de correspondência e 
conferências telefônicas, que permitiram que o processo transcorresse bem a despeito da distância.

\section{Conclusão}

A revisão da literatura apontou como fatores de sucesso do processo de transferência do conhecimento a seleção dos membros das equipes, 0 estabelecimento de relações de confiança, alta motivação para participar e compartilhar, o apoio da organização, a existência de uma equipe preparada para receber o conhecimento e a mente aberta de quem o transmite, para aceitar, também, receber conhecimentos complementares. A pesquisa mostrou que todos esses elementos estavam presentes no processo de transferência de conhecimento desenvolvido pela CPPE. O processo foi bem sucedido em capacitar tecnicamente a UB, tendo tido amplo apoio da alta administração. Objetivos foram estabelecidos, os resultados foram avaliados, periodicamente, e os objetivos foram atingidos.

No caso da definição do conhecimento a ser transferido, coube à alta administração da empresa definí-lo como sendo todo aquele necessário ao atingimento dos objetivos da organização, claramente definidos logo no início do projeto e ajustados ao longo dos cinco anos, em função das mudanças da estratégia da empresa.

O fator que mais contribuiu para a transferência do conhecimento adequado para a UB foi a visibilidade conferida pelas reuniões de apresentação dos resultados, que envolviam a alta administração. Se por um lado a visibilidade serviu ao propósito de motivar a equipe pelos ganhos pessoais, também permitiu aos gestores da organização identificar se o conhecimento demandado pela UB estava sendo transferido.

Visitas de média duração (entre sete e dez dias) dos detentores de conhecimento, viagens às fontes de conhecimento, reuniões e encontros presenciais foram parte importante do processo, pois, minimizaram a importância da distância geográfica entre as fontes de conhecimento e a unidade que o demandava. Atividades adicionais de socialização que ocorreram durante as visitas, viagens e reuniões contribuiram para o sucesso. Troca de informações e dados via e-mail e por conferências telefônicas complementaram a comunicação presencial.

Em linha com o que é proposto por diversos autores, que colocam a inovação como elemento chave na estratégia das organizações (KIM; MAUBORGNE, 2005; CHRISTENSEN; RAYNOR, 2005), a estratégia adotada pela CPPE para a Unidade Brasileira, baseada na criação de valor pela inovação, atingiu os principais objetivos de expansão e posicionamento no mercado global. Apoiada pela transferência de conhecimento de outras unidades no período de 1998 a 2003, a UB quadruplicou o número de produtos em seu portfólio, triplicou seu volume de exportação, aumentou seu volume de produção em vinte por cento, aumentou sua produtividade de 15 a $20 \%$, dependendo da linha de produto, e atingiu padrões de qualidade internacional, que permitiram a 
UB expandir sua atuação no mercado latino americano, com a inserção no mercado de quatro países no prazo de três anos.

\section{Referências}

AL-GHASSANI, A. M. et al. Prototype system for knowledge problem definition. Journal of Construction Engineering and Management. May, 2006.

CHANAL, V. Innovation management and organizational learning: a discursive approach. Journal of Innovation Management, v. 7, n. 1, p. 5664, 2004.

CHRISTENSEN, C. M.; RAYNOR, M. E. O crescimento pela inovação: como crescer de forma sustentada e reinventar o sucesso. Rio de Janeiro: Elsevier, 2005.

DIXON, N. M. Common knowledge: how companies thrive by sharing what they know. Boston: Harvard Business School Press, 2000.

DUGUID, P.; BROWN, J. S. Estrutura e espontaneidade: conhecimento e organização. In: FLEURY, M. T. L.; OLIVEIRA JUNIOR, M. de M. Gestão estratégica do conhecimento: integrando aprendizagem, conhecimento e competências. São Paulo, Atlas, 2001. p. 50-85.

FLEURY, M. T. L.; OLIVEIRA JUNIOR, M. de M.; CHILD, J. Compartilhando conhecimento em negócios internacionais: um estudo de caso na indústria de propaganda. In: FLEURY, M. T. L.; OLIVEIRA JUNIOR, M. de M. Gestão estratégica do conhecimento: integrando aprendizagem, conhecimento e competências. São Paulo, Atlas, 2001. p. 294-316.

LEONARD-BARTON, D. Wellsprings of knowledge: building and sustaining the sources of innovation. Boston: Harvard Business School Press, 1995.

KIM, W.C; MAUBORGNE, R. A estratégia do oceano Azul. São Paulo: Campus, 2005.

MINTZBERG, H. Criando organizações eficazes: estruturas em cinco configurações. São Paulo: Atlas, 1995.

NONAKA, I.; TAKEUCHI, H. Criação de conhecimento na empresa. 18 ed. Rio de Janeiro: Elsevier, 1997.

NONAKA, I.; KONNO, N. The concept of "Ba": building a foundation for knowledge creation. California Management Review. v. 40, n. 3, p. 40-54, Spring 1998.

RODRIGUES, S. B. De fábricas a lojas de conhecimento: as universidades e a desconstrução do conhecimento sem clientes. In: FLEURY, M. T. L.; OLIVEIRA JUNIOR, M. de M. Gestão estratégica do conhecimento: integrando aprendizagem, conhecimento e competências. São Paulo, Atlas, 2001. p. 86-117.

SUBRAMANIAM, M.; VENKATRAMAN, N. Determinants of transnational new product development capability: testing the influence of transferring and 
deploying tacit overseas. Knowledge Strategic Management Journal, v. 22, n. 4, p. 359-378, April 2001.

TIDD, J.; BESSANT, J.; PAVITT, K. Managing innovation: integrating technological, market and organizational change. 3 ed. Great Britain: Scotprint, 2005.

ZANDER, U.; KOGUT, B. Knowledge of the firm: combinative capabilities, and the replication of technology. Organization Science, v. 3, n. 3, p. 383397, 1992. 